\title{
Voie antique Rhône-Izernore
}

\section{Alain Melo}

URL : http://journals.openedition.org/adlfi/1601

ISSN : 2114-0502

Éditeur

Ministère de la culture

\section{Référence électronique}

Alain Melo, "Voie antique Rhône-Izernore ", ADLFI. Archéologie de la France - Informations [En ligne], Rhône-Alpes, mis en ligne le 01 mars 2008, consulté le 19 avril 2019. URL : http://

journals.openedition.org/adlfi/1601

Ce document a été généré automatiquement le 19 avril 2019

(c) Ministère de la Culture et de la Communication, CNRS 


\title{
Voie antique Rhône-Izernore
}

\author{
Alain Melo
}

Identifiant de l'opération archéologique : 9800

Date de l'opération : 2008 (PT)

1 Depuis longtemps, les archéologues ont supposé l'existence d'une voie antique qui aurait relié le Rhône (et la voie commerciale qui en suivait le cours : voir Table de Peutinger) aux vallées internes du massif jurassien (Hannezo 1914, Dubois 1942) ; mais aucune trouvaille importante et décisive n'en confirme l'existence (Buisson 1990). La campagne de 2008 visait à établir ou non l'existence d'un passage antique entre haut Séran et vallée de l'Oignin (Combe du Val).

2 La perception d'un tracé linéaire dans ce type de territoire (hautes combes, plateaux, crêts facilement franchissables) impliquait d'observer les réseaux historiques et d'en saisir la chronologie au moins relative. C'est ce qui a été analysé autour du passage col de la Cheminée-Grande Léchère-Meyriat (commune du Grand et Petit-Abergement ; Brénod ; Vieu-d'Izenave, Condamine-La Doye). Cette analyse a révélé :

3 1- Que la construction de la route Belley-Nantua en 1760 avait entraîné un important remaniement des réseaux croisés, par captage des chemins de desserte locale; cet axe devint très rapidement - les relevés cadastraux de 1837 (un petit siècle plus tard) entérinent totalement la nouveauté - la colonne vertébrale des cheminements locaux.

$4 \quad 2$ - Cette réorganisation est sans doute à l'origine de la perception qu'eurent les premiers archéologues de la voirie antique bugiste qui virent dans ce tracé ou presque un axe romain (Hannezo 1914) ou qui a contrario imaginèrent d'autres passages, notamment par les pentes très raides et instables qui dominent Les Neyrolles, difficilement aménageables sans grands travaux (Dubois 1942).

5 3- La reconstitution par l'archéologie (repérages de tronçons reliques ou fossiles) et la documentation médiévale proposent une nouvelle vision des réseaux antérieurs à 1760 : cheminements principaux par combes et vallées prédominaient; mais les crêts étaient 
facilement franchis par les nombreux « golets » qui les percent, essentiellement pour des liaisons entre agglomérations, semble-t-il.

6 4- Toutefois, s'il y eut une route antique via le principal de ces passages, aujourd'hui dénommé col de la Cheminée-Grande Léchère, le terrain ne conserve pas de traces qui permettent de l'affirmer; un simple cheminement est bien entendu possible, et la possibilité de liaison entre vallée du Séran et Combe du Val tout à fait plausible.

7 5- Reste une question qui n'a pas été approfondie, et qui pourrait contribuer à comprendre l'organisation des réseaux routiers montagnards : celle de la "géopolitique " locale. En effet, curieusement, l'évêché de Genève outrepasse la ligne de crête qui fermait autrefois à l'ouest le Valromey. Les villages Brénod et Champdor qui constituent cette excroissance territoriale dans le territoire du diocèse de Lyon seraient-ils des «têtes de cols » de l'antique Valromey?

6- Enfin, quelles pouvaient être les raisons antiques d'établir une relation pérenne entre les deux vici de Vieu-en-Valromey et d'Izernore? Difficile de répondre sans une connaissance plus approfondie de la place de ces agglomérations dans leur territoire.

9 Signalons également la découverte, dans la forêt de Meyriat (communes de Condamine et de Vieu-d'Izenave), sur un itinéraire au moins médiéval (cité en 1130 : via Balmeti, chemin du Balmay - com. de Vieu-d'Izenave - à la chartreuse de Meyriat), de deux tronçons à ornières creusées dans la roche (écartement homogène d'à peine plus d'un mètre). Il pourrait s'agir de traces confirmant l'usage important pendant longtemps des traineaux en toutes saisons pour l'exploitation forestière. Un document de 1280 (Comptes de la châtellenie de Lompnes) l'atteste clairement; une interdiction de 1746 répétée en 1782 (AD Ain, C 1069) montre l'impact négatif de cet usage sur les chemins de montagne, et donc sa probable disparition progressive après la fin du XVIII ${ }^{\mathrm{e}} \mathrm{s}$.

\section{INDEX}

Index chronologique : Antiquité romaine

Thèmes : voie romaine

Index géographique : Rhône-Alpes, Ain (01)

operation Prospection thématique (PRT)

\section{AUTEUR}

\section{ALAIN MELO}

Bénévole 